\title{
Platelet Rich Plasma in Arthroscopically Repaired Rotator Cuff Muscle: A Meta-analysis of Randomized Controlled Trials
}

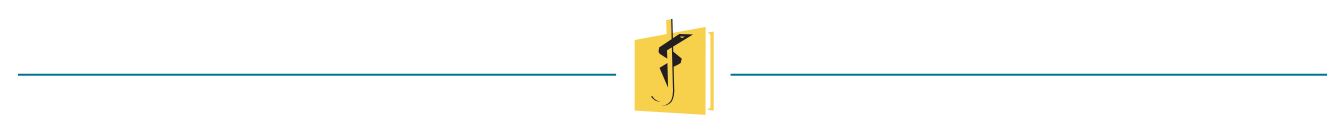

Patrick Henry Lorenzo', Jeremy James C. Munji M.D. ${ }^{2}$

\section{ABSTRACT}

Background Platelet-rich plasma (PRP) has been used as a biologic augmenter in arthroscopically repaired rotator cuff muscle. The objective of this meta-analysis is to compare the clinical and structural outcomes of patients with and without PRP supplementation in arthroscopic rotator cuff repair.

Methods A systematic search in different online databases was done to evaluate studies involving PRP supplementation in arthroscopically repaired rotator cuff muscle, reviewing the re-tear rates, pain scale and functional shoulder scores in groups with and without PRP supplementation.

Results Six studies were eligible for the meta-analysis. Arthroscopically repaired rotator cuff with PRP supplementation showed statistically better clinical and structural outcomes compared to the group who did not receive supplementation.

Conclusion PRP as a biologic augmenter can decrease the re-tear rates as well as pain scale and can improve the functional shoulder scores of patients with arthroscopically repaired rotator cuff muscle.

Patrick Henry Lorenzo

phlorenzo17@gmail.com

1 University of Santo Tomas Hospital, Orthopaedics

2 Faculty of Medicine and Surgery, University of Santo Tomas

\section{INTRODUCTION}

Arthroscopic rotator cuff repair has been widely used to manage full-thickness tears in rotator cuff muscles as it is associated with less pain and better functional outcomes in the early recovery period [1]. Despite advances in the fixation technique, tendon to bone healing still remains unpredictable. A high re-tear rate ranging from 10\% to $57 \%$ has been observed from rotator cuff tear sizes ranging from $\leq 2$ to $>8 \mathrm{~cm}^{2}$ after arthroscopic repair [2].

Platelet-rich plasma (PRP) is a refined product of autologous blood with a platelet concentration greater than that of whole blood [3]. Several different commercial preparation kits are available in the market but basically, autologous blood of about $20-30 \mathrm{~mL}$ is extracted from the patient after which the blood is centrifuged for about 5 to 7 minutes, the serum plasma separated using another syringe and injected into the affected area [5].

Platelets are a source of high concentrations of several growth factors that are able to stimulate cell proliferation and provide a temporary matrix that fills the defect sites and serves as a matrix for cell migration and tissue remodeling [4]. It is rich in biologic factors (growth factors, cytokines, proteins, cellular components) essential for the body's response to injury [3]. Hence, PRP can play a vital role in the biologic augmentation of tissue repair. 
Various randomized controlled trials exploring the role of PRP in the augmentation of arthroscopically repaired rotator cuff muscles show mixed outcomes. There were two published meta-analyses done by Zhao J et.al. [4] and Cai Y et. al. [9] using level 1 and 2 type of evidences during the years 2011 to $2014[4,9]$. Both studies showed no significant difference between patients with and without PRP supplementation after arthroscopic repair of rotator cuff muscle. In contrast to recently published studies, one meta-analysis conducted by Warth et al. [11] showed significant reduction in re-tear rates after PRP supplementation [11]. Two recent level 1 evidences, not included in those published meta-analysis showed significant reduction of re-tear rates after PRP supplementation $[8,10]$. As a result, there is a conflict in the efficacy whether PRP has a role in augmentation of arthroscopically repaired rotator cuff muscles $[4,6,7,8,9,10,11]$.

The objectives of this meta-analysis are: (1) to determine the re-tear rates among patients with arthroscopically repaired full-thickness rotator cuff tears who received PRP supplementation using meta-analysis (2) to determine if PRP supplementation can decrease the pain scale of patients with arthroscopically repaired full-thickness rotator cuff tears using meta-analysis; and (3) to determine if PRP supplementation will improve shoulder scores of patients with arthroscopically repaired full-thickness rotator cuff tears using meta-analysis.

\section{METHODOLOGY}

\section{Search Methods and Inclusion Criteria}

A structural search was done using the PubMed, The Cochrane Library, Google Scholar and EMBASE databases starting from the year 2012 to 2018 . Search terms used include: "Platelet-Rich Plasma AND Rotator Cuff Repair". Furthermore, we searched the following journal contents in the past 3 years for randomized controlled trials: Arthroscopy: The Journal of Arthroscopic and Related Surgery, The American Journal of Sports Medicine, The Journal of Bone and Joint Surgery, The Bone and Joint Journal, Clinical Orthopaedics and Related Research, and the Journal of Shoulder and Elbow Surgery [4]. Local publications and electronic databases were also utilized so as to provide a thorough literature review. Unpublished gray literature was also reviewed through consultation with the research adviser.
Only level 1 randomized, controlled trials with full texts available were considered for this review as this type of study gave high quality data with the least bias. Available literature included have the following: (1) a target population of full-thickness rotator cuff tears requiring arthroscopic repair; (2) study designs comparing the outcomes of arthroscopic rotator cuff surgery with or without the use of PRP; (3) a minimum of 12-month follow-up; and (4) one or more outcomes of interest postoperatively leg, retear rate, shoulder score and complications) [4].

\section{Data Collection and Analysis}

Two authors independently scanned the records retrieved from the searches and excluded studies which did not meet the inclusion criteria. In cases of disagreement between the two authors discussion with the research adviser to resolve conflicts was done. All studies that met the criteria were subjected to assessment of methodological quality. Those with poor methodological quality were not considered in the review.

Two authors independently extracted details and data and recorded them using the Cochrane Collaboration Data Extraction Template. The disagreement between the two authors was resolved by a discussion with the research adviser. The primary outcome measure of interest was the structural outcome which was expressed as re-tear rate. Secondary outcome measures of interest include the clinical outcomes namely: pain expressed as VAS and functional outcomes grade using various shoulder scores.

Methodological quality was assessed by the two authors. A detailed explanation of the randomization and blinding process was stated in the study designs for considered trials. A clearly stated follow-up period and low dropout rate of less than $20 \%$ was present in the methodology for considered trials. Studies which met all four criteria with good methodological quality were considered for this review.

Both clinical heterogeneity (eg, differences among patients, interventions and outcomes) and statistical heterogeneity (variation between trials in the underlying treatment effects being evaluated) were assessed in this study. To establish consistency in the study results, statistical heterogeneity between studies was tested using a standard I-square test. The $\mathrm{I}^{2}$ estimate examines the percentage of total variation across studies resulting from heterogeneity rather than by 
chance. According to the Cochrane Handbook, heterogeneity is considered not important between $0 \%$ and $40 \%$, moderate between $30 \%$ and $60 \%$, substantial between $50 \%$ and $90 \%$, and considerable between $75 \%$ and $100 \%$. Therefore, an $\mathrm{I}^{2}$ of less than $60 \%$ was accepted in this meta-analysis, and a random-effects model was used. The test for significance was two-tailed and $p$-value of $<0.05$ was deemed significant.

A thorough risk-of-bias assessment was undertaken to identify factors that may alter the results of this analysis. Two authors independently evaluated each included study and documented their potential for selection bias, performance bias, detection bias, attrition bias and reporting bias using the Cochrane tool for assessing the risk of bias in randomized trials.

The Review Manager 5.3 software program provided by The Cochrane Collaboration was used for graphic representation of the pooled data. Continvous data was measured as mean differences with $95 \% \mathrm{Cls}$. In addition, only outcomes reported by at least four or more studies were pooled to ensure good validity and high quality of pooled results because less than four references would create an excessive opportunity for bias [4].

\section{RESULTS}

This meta-analysis was conducted according to the guidelines of Preferred Reporting Items for Systematic Review and Meta-Analysis (PRISMA).

\section{Study Selection}

Two hundred eight titles were initially found. Ninetyone records were pooled using the PUBMED database while 117 records were identified from different online publication journals. Figure 1 shows the flow diagram outlining the study selection process. Six level 1 randomized controlled trials were eligible for the study. Two of the six were made by the same author but was done at two separate time periods.

\section{Study Characteristics}

Table 1 summarizes the individual study characteristics. All 6 studies included were randomized controlled trials with at least a 1 -year follow-up period. A total of 410 patients were included in the meta-analysis; of these 206 were randomly assigned to the group with PRP augmentation, while 204 patients were assigned to the group without PRP. All 6 studies assessed the re-tear rates, which was the primary outcome of this study. For the secondary outcomes, all 6 studies measured the pain scale of patients, only 5 studies measured the outcome after 1-year follow-up. Four studies measured the Constant-Murley scores of the subjects after a 1 -year follow-up.

\section{Risk of Bias Assessment}

Figures 2 and 3 summarize the risk of bias per study. The risk of selection bias was found to be low as only randomized studies were considered. Performance bias was likewise low since blinding of both the subjects and assessors were done in a majority of studies. Attrition bias was somewhat unclear since almost all studies did not mention an intention to treat analysis, although most of the included dropout rates were less than 10\%. Publication bias was found to be low for all outcomes based on visual examination of funnel plots (appendices $A, B, C$ ).

\section{Re-tear Rates}

Figure 4 . shows the forest plot for the re-tear rates across 6 studies. Re-tears occurred in $18(8 \%)$ of 211 patients in the PRP group and 49 (23\%) of 209 patients in the group without PRP. The difference was significant $(p<0.00001)$ favoring a lower re-tear rate for subjects with PRP augmentation. The test of heterogeneity showed no heterogeneity $\left(l^{2}=0 \%\right)$.

\section{Pain Scale}

Figure 5 shows the forest plot for pain scale using VAS after 12 months' follow-up. Five out of 6 studies were included in the analysis. The group with PRP showed a decrease in pain scale measured using VAS as compared to the group without PRP. The difference was significant (mean difference, -0.14; $95 \% \mathrm{Cl},-0.23,-0.05)$. The test for heterogeneity was acceptable $\left(l^{2}=4 \%\right)$.

\section{Constant-Murley Score}

Figure 6 shows the forest plot of the Constant-Murley Scores after 12 months' followup across 5 studies. 


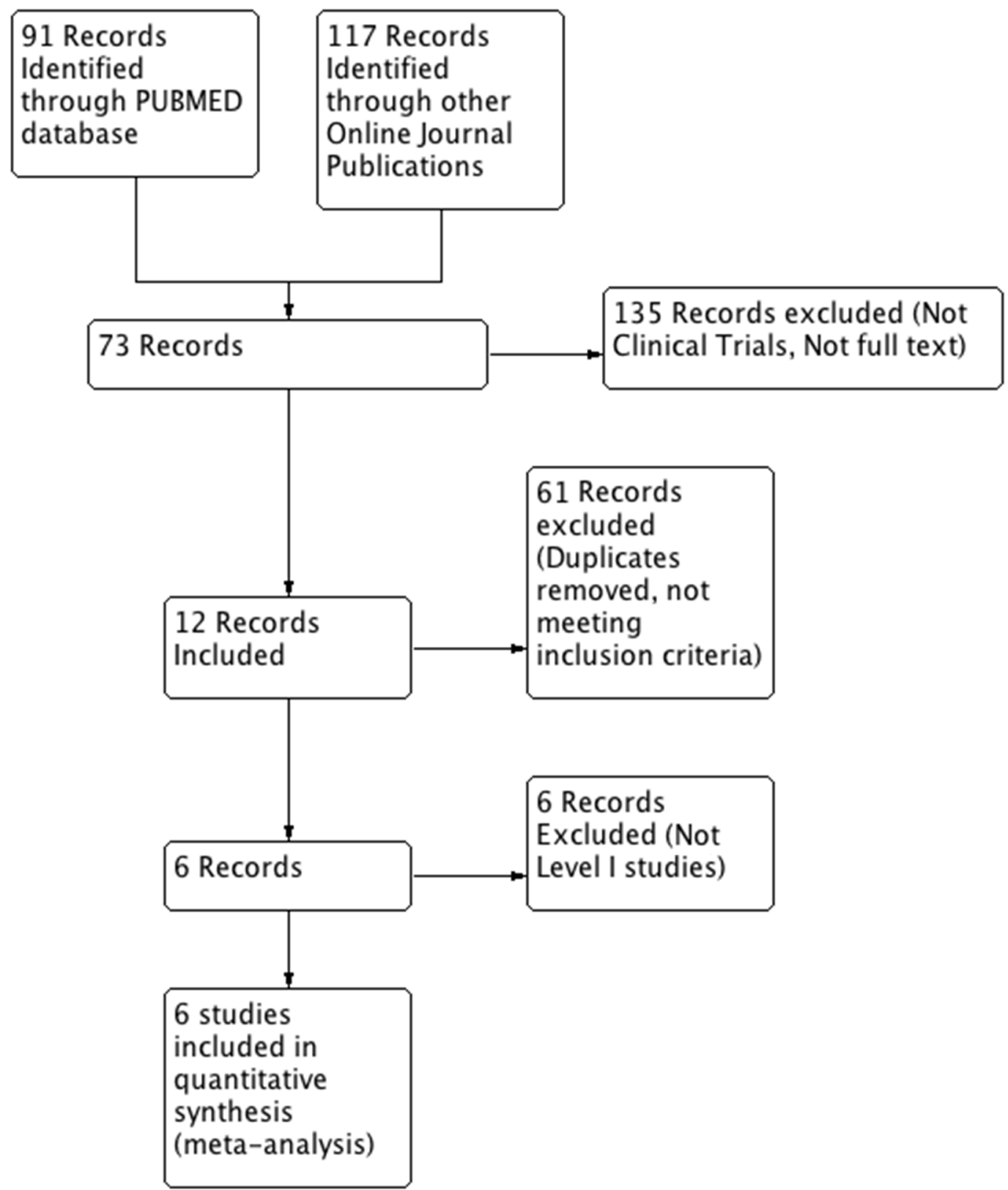

Figure 1. Flow Diagram summarizing the process by which 6 studies were identified

The group with PRP augmentation showed higher Constant-Murley Scores as compared to those without PRP. The difference was significant (mean difference $3.36 ; 95 \% \mathrm{Cl}, 1.54,5.18)$. The test of heterogeneity showed no heterogeneity $\left(\left.\right|^{2}=0 \%\right)$.

\section{DISCUSSION}

The results of this meta-analysis showed the efficacy of PRP as an augmenting biologic agent for patients who underwent arthroscopically repaired rotator cuff muscle. In contrast to previously reported meta-analyses $[4,1]$, PRP as an augmenting agent reduces the re-tear rates, reduces the pain one year after the operation and improves the functional outcome of patients who underwent arthroscopic repair of rotator cuff muscles using the Constant-Murley Scale.

The result was consistent with the result of the meta-analysis published by Cai et al. [9] of re-tear rates showing a significant decrease in the re-tear rates of minor to moderately sized rotator cuff tears, however, it did not show a significant difference for large tears [9]. However, the subgroup analysis for large tears has a small sample size which was considered one of the limitations of the study [9]. A recent study by Pandey et.al. [8] showed conflicting results when it comes to re-tear rates compared to the study done 
Table 1. Summary of Study Characteristics of included in the study. I: Intervention, C: Control Group

\begin{tabular}{|c|c|c|c|c|c|c|c|}
\hline Study(Year) & $\begin{array}{l}\text { Number of } \\
\text { Patients }\end{array}$ & Type of Repair & PRP Type & Application & Follow Up & Outcome Measures & $\begin{array}{l}\text { Level of } \\
\text { Evidence }\end{array}$ \\
\hline $\begin{array}{l}\text { Jo et.al. } \\
(2013)\end{array}$ & $\begin{array}{l}\mathrm{I}: 24 \\
\mathrm{C}: 24\end{array}$ & $\begin{array}{l}\text { Suture Bridge } \\
\text { Technique }\end{array}$ & PRP & $\begin{array}{l}\text { Bone Tendon } \\
\text { Interface }\end{array}$ & 12 months & $\begin{array}{l}\text { Retear Rate (MRI, CTA, } \\
\text { VAS, CS, ASES, DASH) }\end{array}$ & Level I \\
\hline $\begin{array}{l}\text { Malavota } \\
\text { et.al.(2014) }\end{array}$ & $\begin{array}{l}1: 27 \\
C: 28\end{array}$ & $\begin{array}{l}\text { Single Row } \\
\text { Repair }\end{array}$ & PRP & $\begin{array}{l}\text { Bone Tendon } \\
\text { Interface }\end{array}$ & $\begin{array}{l}3,6,12,24 \\
\text { months }\end{array}$ & $\begin{array}{l}\text { Retear Rate (MRI), UCLA, } \\
\text { CS, VAS }\end{array}$ & Level I \\
\hline $\begin{array}{l}\text { Zhang et.al. } \\
(2015)\end{array}$ & $\begin{array}{l}1: 32 \\
C: 30\end{array}$ & $\begin{array}{l}\text { Double Row } \\
\text { Repair }\end{array}$ & PRP & $\begin{array}{l}\text { Bone Tendon } \\
\text { Interface }\end{array}$ & 12 months & $\begin{array}{l}\text { Retear Rate (MRI), DASH, } \\
\text { CS, VAS }\end{array}$ & Level I \\
\hline $\begin{array}{l}\text { Jo et.al. } \\
\text { (2015) }\end{array}$ & $\begin{array}{l}1: 37 \\
C: 37\end{array}$ & $\begin{array}{l}\text { Suture Bridge } \\
\text { Technique }\end{array}$ & PRP & $\begin{array}{l}\text { Bone Tendon } \\
\text { Interface }\end{array}$ & $\begin{array}{l}3,6,12 \\
\text { months }\end{array}$ & $\begin{array}{l}\text { Retear Rate (MRI), ASES, } \\
\text { UCLA, SST }\end{array}$ & Level I \\
\hline $\begin{array}{l}\text { Flury et.al. } \\
(2016)\end{array}$ & $\begin{array}{l}\mathrm{I}: 54 \\
\mathrm{C}: 58\end{array}$ & $\begin{array}{l}\text { Double Row } \\
\text { Repair }\end{array}$ & PRP & $\begin{array}{l}\text { Bone Tendon } \\
\text { Interface }\end{array}$ & $\begin{array}{l}3,6,24 \\
\text { months }\end{array}$ & $\begin{array}{l}\text { Retear Rate (MRI, US), CS, } \\
\text { VAS, ASES, DASH }\end{array}$ & Level I \\
\hline $\begin{array}{l}\text { Pandey } \\
\text { et.al.(2016) }\end{array}$ & $\begin{array}{l}\text { I:56 } \\
C: 54\end{array}$ & $\begin{array}{l}\text { Single Row } \\
\text { Repair }\end{array}$ & PRP & $\begin{array}{l}\text { Above Repaired } \\
\text { Cuff }\end{array}$ & $\begin{array}{l}6,12,24 \\
\text { months }\end{array}$ & $\begin{array}{l}\text { Retear Rate (US), CS, VAS, } \\
\text { UCLA, ASES }\end{array}$ & Level I \\
\hline
\end{tabular}

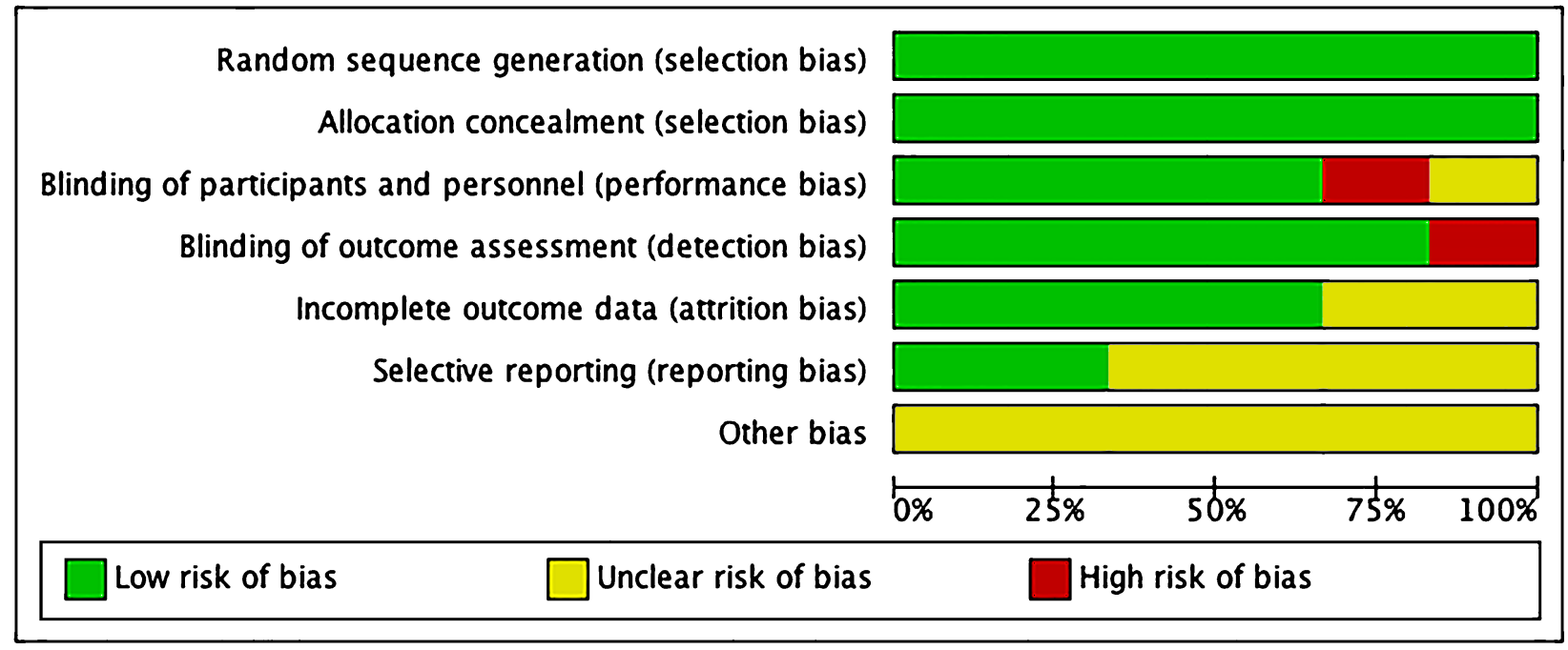

Figure 2. Risk of Bias Graph

by Cai et.al. [9]. In his study, they concluded that PRP showed significant difference as to lower re-tear rates in large rotator cuff tears in contrast to medium sized tears, which showed no significant difference in re-tear rates [8]. The contrasting conclusions may be attributed to various factors; small sample sizes over a wide range of rotator cuff tears, differences in the techniques of repair of the rotator cuff which can mask the effect of PRP, and the etiology of tears whether it is traumatic or degenerative since degenerative tears have a lower healing potential as compared to traumatic tears [8].

Clinical outcomes investigated in this meta-analysis were the pain scale measured using VAS and the Constant-Murley score. Only one previous meta-analysis investigated the effect of PRP in terms of decreasing the pain scale of patients after arthro- scopic rotator cuff repair, it showed no significant difference [11]. The difference in results can be explained by the previous meta-analysis included level II studies. Two other meta-analyses revealed no significant difference in Constant-Murley Scores after 1 year of follow-up with the use of PRP for augmentation of arthroscopically repaired rotator cuff $[4,9,11]$. The conflicting results from this meta-analysis may be attributed to two factors. The studies conducted by Warth et.al. [11] and Zhao et.al. [4] included 1 level II study which may be a source of skewed results $[4,11]$. Also, the study done by Cai et.al. [9] has a relatively small sample size as compared to this meta-analysis.

Although favorable results were seen in this meta-analysis, it is not without limitations. First, the decision to include only level I studies to increase the 


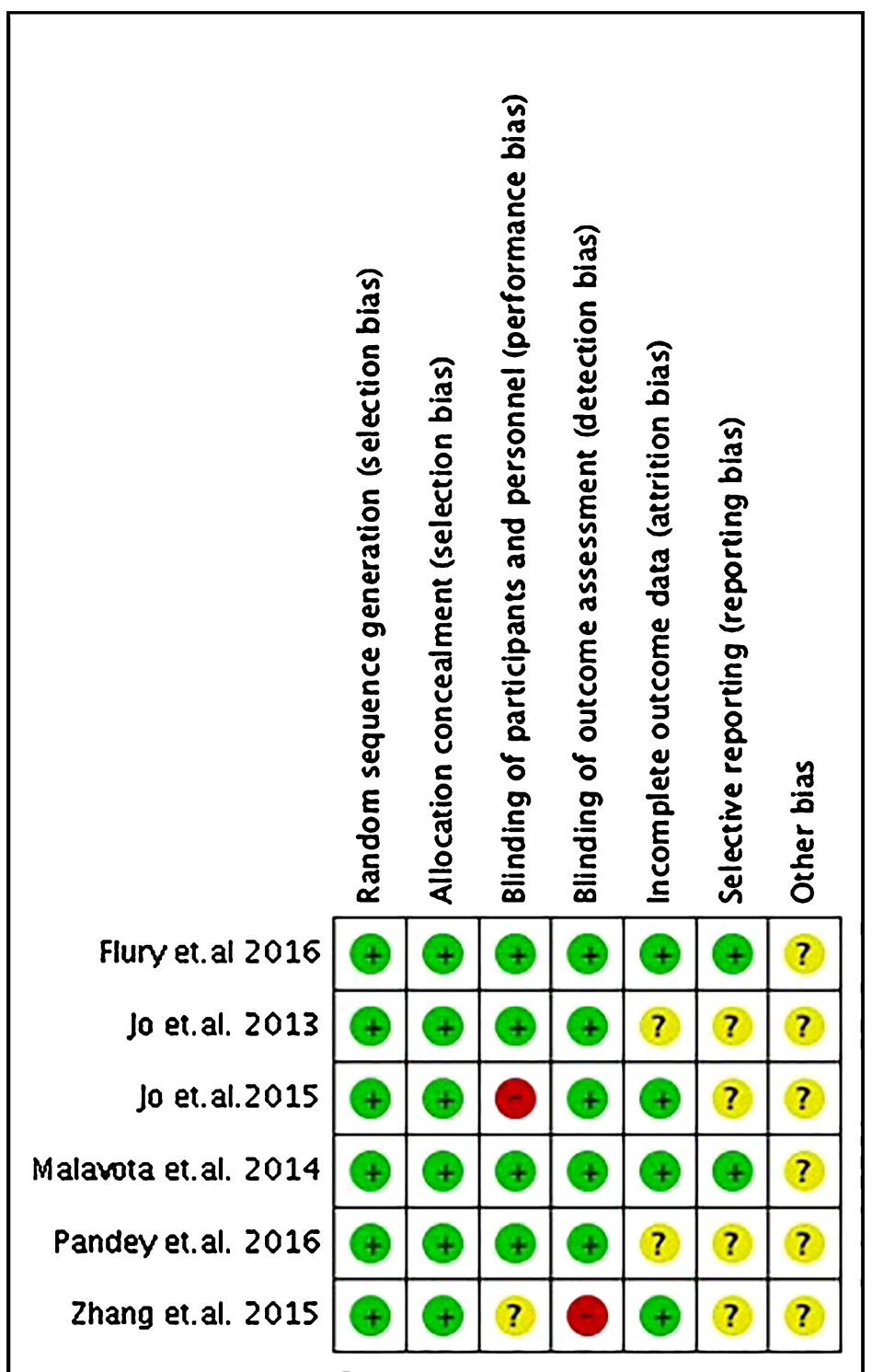

Figure 3. Risk of Bias per Study

\begin{tabular}{|c|c|c|c|c|c|c|c|c|c|c|}
\hline Study or Subgroup & \multicolumn{2}{|c|}{ With PRP } & \multicolumn{2}{|c|}{ Without PRP } & \multicolumn{3}{|c|}{ Odds Ratio } & \multicolumn{3}{|c|}{$\begin{array}{l}\text { Odds Ratio } \\
\mathrm{M}-\mathrm{H} \text {, Random, } 95 \% \mathrm{Cl}\end{array}$} \\
\hline Jo et.al. 2013 & 4 & 20 & 10 & 18 & $17.7 \%$ & $0.20[0.05,0.84]$ & 2013 & & & \\
\hline Malavota et.al. 2014 & 2 & 27 & 5 & 27 & $12.1 \%$ & $0.35[0.06,2.00]$ & 2014 & & & \\
\hline Jo et.al.2015 & 1 & 33 & 6 & 30 & $7.7 \%$ & $0.13[0.01,1.11]$ & 2015 & & & \\
\hline Zhang et.al. 2015 & 4 & 30 & 9 & 30 & $21.2 \%$ & $0.36[0.10,1.33]$ & 2015 & & & 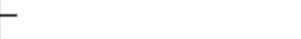 \\
\hline Flury et.al 2016 & 5 & 49 & 9 & 54 & $26.7 \%$ & $0.57[0.18,1.83]$ & 2016 & & & \\
\hline Pandey et.al. 2016 & 2 & 52 & 10 & 50 & $14.7 \%$ & $0.16[0.03,0.77]$ & 2016 & & & \\
\hline Total $(95 \% \mathrm{CI})$ & & 211 & & 209 & $100.0 \%$ & $0.30[0.16,0.55]$ & & & & \\
\hline Total events & 18 & & 49 & & & & & & & \\
\hline $\begin{array}{l}\text { Heterogeneity: } \mathrm{Tau}^{2}= \\
\text { Test for overall effect: }\end{array}$ & $\begin{array}{l}0.00 ; \text { Chi } \\
Z=3.92\end{array}$ & $\begin{array}{l}2=2.8 \\
(P<0\end{array}$ & $\begin{array}{l}30, \mathrm{df}=5 \\
0001)\end{array}$ & $(P=0$. & $.73) ; 1^{2}=$ & $0 \%$ & & $\frac{1}{0.01}$ & $\begin{array}{c}0.1 \\
\text { Favors with PRP }\end{array}$ & $1_{\text {Favors without PRP }}^{1} 100$ \\
\hline
\end{tabular}

Figure 4. Forest Plot of Retear Rates

power of our analysis may have induced reporting bias to the results as seen in the risk of bias assessment. Second, although the clinical outcomes can be measured objectively using VAS and the Constant-Murley score, they are still subjective in nature and the results are still at risk of reporting bias.

\section{CONCLUSION}

PRP as a biologic augmenter for repair has a role in the treatment of rotator cuff tear. It can decrease the re-tear rates, reduce pain scales and improve the functional shoulder scores in terms of the 


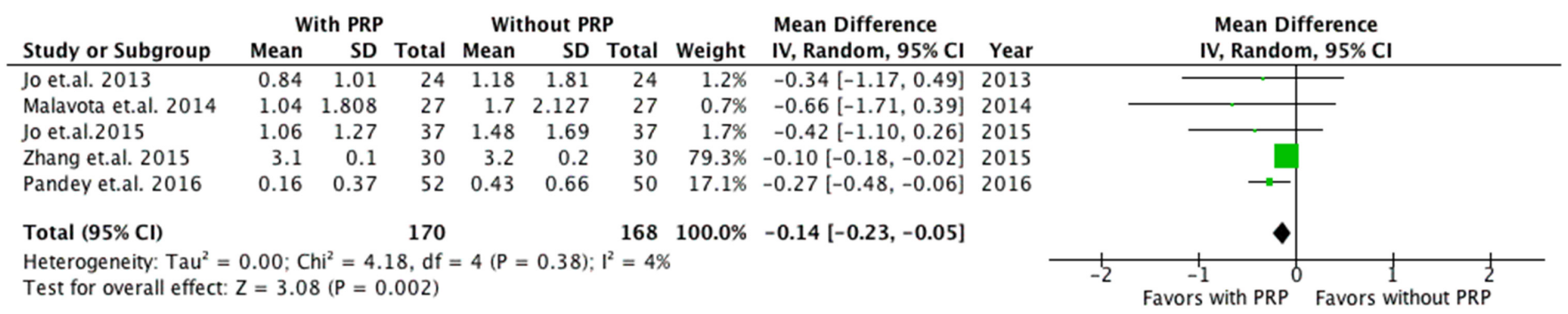

Figure 5. Forest Plot of Plain Scale Using VAS after 12 months Follow-Up

Constant-Murley Score. One of the limitations of this study is the possibility of reporting bias as only level 1 studies were included. Another limitation identified is the small sample size of the total study population.
A study utilizing more randomized controlled trials would be better in order to determine the magnitude of its treatment effect. 


\section{REFERENCES}

1. Zwaal PVD, Thomassen BJ, Nieuwenhuijse M, et al. Clinical outcome in all-arthroscopic versus mini-open rotator cuff repair in small to medium-sized tears: a randomized controlled trial in 100 patients with 1-year follow-up. Arthroscopy: The Journal of Arthroscopic \& Related Surgery. 2013;29(2):266-73.

2. Wu X, Murrell G. Intra-operative determinants of rotator cuff repair integrity: An analysis in 500 consecutive repairs. Journal of Science and Medicine in Sport. 2011;14.

3. Zhao J, Zhao L, Jiang $Y$, et al. Platelet-rich plasma in arthroscopic rotator cuff repair: a meta-analysis of randomized controlled trials. Arthroscopy: The Journal of Arthroscopic \& Related Surgery. 2015 Jan;3 1 (1):125-35.

4. Hall M, Band P, Meislin R, et al. Platelet-rich plasma: current concepts and application in sports medicine. Journal of the American Academy of Orthopaedic Surgeons. 2009 Oct; 17(10):602-8.

5. Wang A, Mccann P, Colliver J, Breidahl B, Ackland T. Do postoperative platelet-rich plasma injections accelerate early tendon healing and functional recovery after arthroscopic supraspinatus repair? a randomized controlled trial. Arthroscopy: The Journal of Arthroscopic \& Related Surgery. 2017;33(10).

6. Jo CH, Shin JS, Shin WH, et al. Platelet-rich plasma for arthroscopic repair of medium to large rotator cuff tears. The American Journal of Sports Medicine. 2015;43(9):2102-10.

7. Pandey V, Bandi A, Madi S, Agarwal L. Does application of moderately concentrated platelet-rich plasma improve clinical and structural outcome after arthroscopic repair of medium-sized to large rotator cuff tear? A randomized controlled trial. Journal of Shoulder and Elbow Surgery. 2016;25(8):1312-22.

8. Zhang Q, Ge HA, Zhou J, Cheng B. Are platelet-rich products necessary during the arthroscopic repair of fullthickness rotator cuff tears: a meta-analysis. PLoS ONE. 2013;8(7).

9. Jo C, Shin J, et al. Platelet-rich plasma for arthroscopic repair of large to massive rotator cuff tears: a randomized, single-blind, parallel-group trial. The American Journal of Sports Medicine. 2013 Aug 6;41(10):2240-8.

10. Warth RJ, Dornan GJ, James EW, Horan MP, Millett PJ. Clinical and structural outcomes after arthroscopic repair of full-thickness rotator cuff tears with and without platelet-rich product supplementation: a meta-analysis and meta-regression. Arthroscopy: The Journal of Arthroscopic \& Related Surgery. 2015;31 (2):306-20.

Open Access This article is licensed under a Creative Commons Attribution 4.0 International License, which permits use, sharing, adaptation, distribution and reproduction in any medium or format, as long as you give appropriate credit to the original author(s) and the source, provide a link to the Creative Commons license, and indicate if changes were made. The images or other third party material in this article are included in the article's Creative Commons license, unless indicated otherwise in a credit line to the material. If material is not included in the article's Creative Commons license and your intended use is not permitted by statutory regulation or exceeds the permitted use, you will need to obtain permission directly from the copyright holder. To view a copy of this license, visit http://creativecommons.org/licenses/ by/4.0/.

\section{APPENDICES}
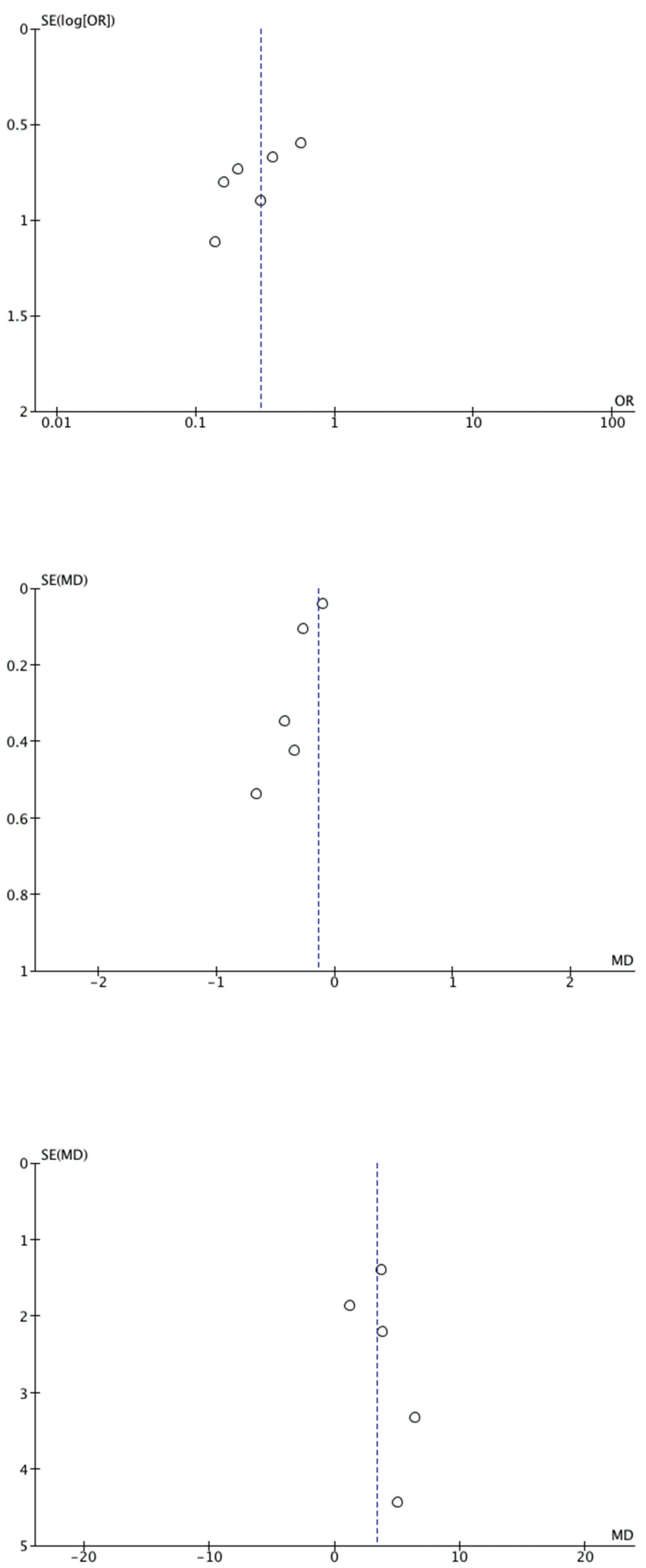